\title{
CRAQUEAMENTO TERMOCATALÍTICO DA BORRA DE NEUTRALIZAÇÃO DO ÓLEO DE PALMA EM ESCALA DE BANCADA
}

\author{
M. C. SANTOS ${ }^{1}$, E. R. L. LIMA ${ }^{2}$, D. H. S. ABREU ${ }^{3}$, R. M. LOURENÇO ${ }^{4}$, D. \\ E. L. LHAMAS ${ }^{5}$, L. P. BORGES ${ }^{6}$ e N. T. MACHADO ${ }^{7}$ \\ 1,3,5 Universidade Federal do Pará, PRODERNA \\ ${ }^{4}$ Universidade Federal do Pará, PPGEQ \\ ${ }^{2,7}$ Universidade Federal do Pará , Faculdade de Engenharia \\ Química \\ ${ }^{6}$ Instituto Militar de Engenharia, Seção Química \\ E-mail: marceloenqui@bol.com.br
}

\begin{abstract}
RESUMO - Este trabalho investiga o processo de craqueamento termocatalítico da borra de neutralização, matéria-prima de baixo valor agregado, resultante do processo de neutralização do óleo de palma. Os testes foram realizados num reator de vidro borosilicato de $100 \mathrm{~mL}$, inserido em um forno cilíndrico de resistência cerâmica e controle digital de temperatura e taxa de aquecimento, acoplado a um condensador de vidro borosilicato e placa de agitação magnética com controle de frequência. $\mathrm{O}$ parâmetro experimental avaliado foi o teor do catalisador carbonato de cálcio (5 e $10 \%$ $\mathrm{m} . / \mathrm{m}$ ) na temperatura de craqueamento de $440^{\circ} \mathrm{C}$, no rendimento e qualidade dos produtos líquidos orgânicos (PLOs), através da caracterização físico-química (índice de acidez e índice de saponificação, densidade e índice de refração) e análise composicional por espectroscopia de infravermelho. O carbonato de cálcio foi caracterizado por difratometria de raios-X (DRX) e análise térmica (TG/DTA). Os resultados mostraram que o aumento do teor de catalisador contribuiu na redução do rendimento. Em todos os espectros de infravermelho foi observado à presença de compostos oxigenados, hidrocarbonetos alifáticos e olefínicos.
\end{abstract}

\section{INTRODUÇÃO}

Atualmente, o consumo de energia vem aumentando significativamente, quando comparado com anos anteriores, devido o rápido crescimento da população combinado com o sucessivo desenvolvimento econômico, o qual está atrelado à dependência dos recursos naturais da terra, por exemplo, os combustíveis fósseis (Nam, 2011).

A produção de bicombustíveis, com frações do diesel e gasolina, pode ser vista como uma rota alternativa para a produção de combustíveis a partir de óleos ou gorduras naturais, caracterizando-se assim como uma rota tecnologicamente correta, pois são livres de nitrogênio e compostos de enxofre, fatos esses que possibilitam na diminuição do efeito estufa e na redução da poluição atmosférica local (Twaiq et al., 2003). 
Diante das diversas fontes de óleos e gorduras com potencial para a produção de um biocombustível que possa se enquadrar como um substituto parcial ou total do diesel fóssil devese levar em consideração três aspectos fundamentais antes de utilizá-las: viabilidade técnica, e econômica para a produção, e obtenção do óleo ou gordura em escala suficiente para atender a demanda pelo biocombustível; viabilidade técnica, e econômica para transformá-lo em biocombustível, e garantias de que a qualidade do biocombustível produzido será compatível com o seu uso em motores veiculares ou estacionários (Suarez, 2009).

Os resíduos de óleos vegetais e gorduras estão se tornando matérias-primas bastante visadas ultimamente por serem economicamente e ambientalmente vantajosos. Tais materiais tem o potencial de reduzir o consumo de combustíveis não renováveis e a quantidade de resíduo depositado no meio ambiente (Ratton, 2012).

A borra de óleo ou sais de ácidos carboxílicos é uma emulsão oleosa alcalina constituída por água, sais de ácidos graxos saponificados (sabão), fosfatídeos, triglicerídeos, pigmentos e outros compostos presentes em menor quantidade. Dentro do processo de refino de óleos vegetais, a borra é formada durante a etapa de neutralização dos ácidos graxos livres com hidróxido de potássio ou hidróxido sódio (Park et al., 2008). A borra de neutralização é uma matéria-prima alternativa para produzir biocombustíveis semelhantes ao óleo diesel derivado de petróleo através do craqueamento térmico ou catalítico (Abreu, 2013).

A reação de craqueamento ou pirólise de triacilglicerídeos consiste na quebra de ligações envolvendo os grupos funcionais éster e, em menor grau, as cadeias carbônicas dos triésteres, as quais são caracterizadas como componentes dos óleos e gorduras responsáveis pela formação de uma mistura de compostos constituída em sua maioria de hidrocarbonetos e, em menor quantidade, compostos oxigenados (Suarez, 2009). A pirólise de diferentes triacilglicerídeos foi usada em diferentes países, durante a primeira e a segunda guerra mundial, como fonte de obtenção de combustíveis alternativos ao petróleo (Chang e Wan, 1947). A Figura 1 mostra um esquema geral da reação de craqueamento de óleos e gorduras.

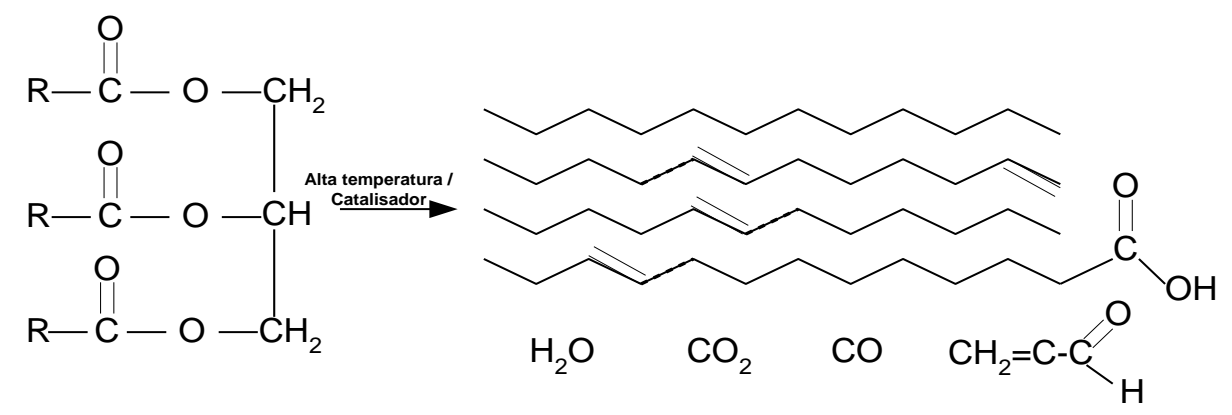

Figura 1 - Reação de craqueamento de triacilglicerídeos.

A reação de craqueamento ocorre em temperaturas superiores a $350{ }^{\circ} \mathrm{C}$, na presença ou ausência de catalisadores, em diversas etapas distintas e consecutivas (Idem, 1996). Na primeira etapa, mostrada na reação 1 da Figura 2, que é chamada de craqueamento primário são formadas duas moléculas de ácidos carboxílicos, uma molécula de ceteno e acroleína. A mistura formada é extremamente instável nas condições reacionais e reage rapidamente, conforme mostrado na reação 2 da Figura 2, formando novos ácidos carboxílicos, hidrocarbonetos, aldeídos e cetonas. Numa segunda etapa de craqueamento, chamada de craqueamento secundário, verifica-se a 
desoxigenação dos produtos formados no craqueamento primário, principalmente os ácidos carboxílicos. De fato, os ácidos carboxílicos formados durante o craqueamento primário e reações de rearranjo são desoxigenados no craqueamento secundário, que pode ocorrer por duas rotas distintas: descarboxilação e descarbonilação, conforme mostrado nas reações 3 e 4 da Figura 2 (Gusmão, 1989). Posteriormente, inúmeras reações consecutivas podem ocorrer, tais como: rearranjos, acoplamentos radicalares, craqueamento das cadeias carboxílicas, entre outras.

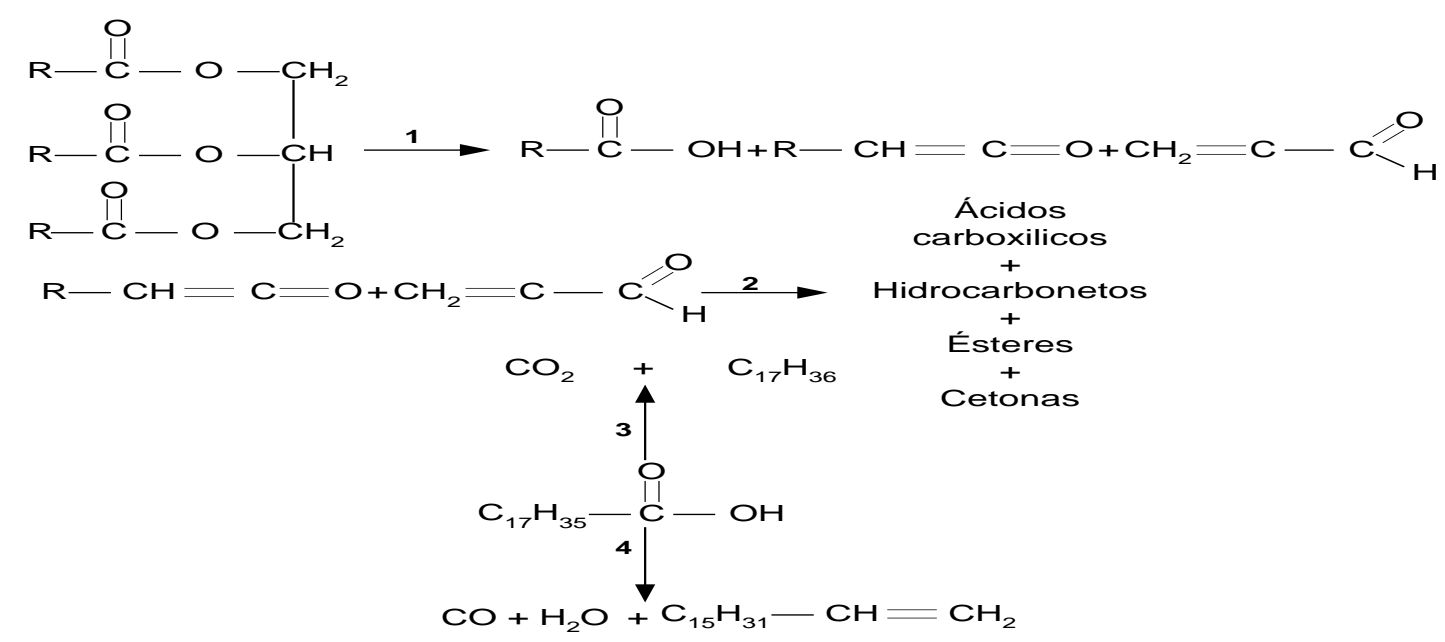

Figura 2 - Algumas reações que ocorrem durante o processo de craqueamento.

A utilização de resíduos de processos industriais orgânicos, dentre estes, a borra de neutralização do óleo palma, matéria prima alternativa para obtenção de combustíveis, tem sido levantada como proposta neste trabalho. Neste contexto investigou-se o processo de craqueamento termocatalítico da borra de neutralização em uma unidade de bancada, constituída por um reator de vidro borosilicato $(100 \mathrm{~mL})$, utilizando carbonato de cálcio $\left(\mathrm{CaCO}_{3}\right)$ como catalisador de processo na temperatura de operação de $440^{\circ} \mathrm{C}$.

\section{MATERIAIS E MÉTODOS}

No procedimento experimental foi utilizado sais de ácidos carboxílicos (sabão de sódio) fornecido pela usina Piloto de Produção de Biodiesel ELETROBRAS/UFPA/IME.

\subsection{Caracterização do Catalisador}

Inicialmente o carbonato de cálcio de grau comercial (Solvay Chemicals International, RJ, Brasil) foi submetido ao processo de secagem em estufa (QUIMIS, Modelo Q-314M122) a $150{ }^{\circ} \mathrm{C}$ por três horas, a fim de retirar a umidade. O teor de catalisador nos experimentos foi de $5 \%$ e $10 \%$ (m./m.) em relação à massa inicial de matéria prima.

A caracterização do carbonato de cálcio foi realizada utilizando as técnicas de difratometria de raios-X (DRX) e análises térmicas (TG/DTA). As análises de TG/DTA foram realizadas em um equipamento Thermal Scienses modelo PL, constituído por um analisador térmico simultâneo STA 1000/1500 da Stanton Redcroft, com forno de formato cilíndrico vertical, termopar constituído de uma liga de Pt-Rh e um cadinho de alumina para aproximadamente $10 \mathrm{mg}$ de amostra. O catalisador foi submetido a uma taxa de aquecimento de $20^{\circ} \mathrm{C} / \mathrm{min}$, na faixa da 
temperatura ambiente até $900{ }^{\circ} \mathrm{C}$, sob atmosfera estática. A técnica de DRX do catalisador foi realizada no Difratômetro de raios X modelo X’PERT PRO MPD (PW 3040/60) da PANalytical (radiação $\mathrm{CuK} \alpha$, filtro de $\mathrm{Ni}$, operando a $40 \mathrm{kV}, 30 \mathrm{~mA}$ e comprimento de onda $(\lambda=0,154 \mathrm{~nm})$, Equipado com o software X'Pert Data Collector, (versão 2.1a). O intervalo de varredura foi para valores de $2 \theta$ variando entre $4^{\circ}$ e $75^{\circ}$. A velocidade de varredura foi de $1^{\circ} \mathrm{mim}^{-1}$ e o passo de leitura foi de $0,01^{\circ}$.

\subsection{Procedimento experimental de craqueamento termocatalítico}

As reações de craqueamento termocatalítico foram realizadas em uma unidade em escala de bancada, constituída por um reator de vidro de borossilicato com as seguintes características: capacidade volumétrica de $100 \mathrm{~mL} ; 15 \mathrm{~cm}$ de altura e $4 \mathrm{~cm}$ de diâmetro. Esse reator é inserido em um forno cilíndrico de resistência cerâmica, e controle digital de temperatura, e taxa de aquecimento sobre uma placa de agitação magnética com controle de frequência. Acima do reator, usa-se uma conexão em forma de "Y". Em uma das extremidades dessa conexão, o gás de alimentação utilizado é o gás inerte nitrogênio $\left(\mathrm{N}_{2}\right)$, cuja vazão é aproximadamente de 0,04 NL.min ${ }^{-1}$, enquanto que na outra extremidade, um condensador de vidro de borossilicato, resfriado com água na temperatura ambiente, é acoplado. A corrente líquida condensada é recolhida em um balão volumétrico de $50 \mathrm{ml}$. O tempo reacional, desse aparato, consiste no momento em que o sistema alcança a temperatura programada, a partir da taxa de aquecimento definida em 10 ${ }^{\circ} \mathrm{C} / \mathrm{min}$, sendo que a temperatura inicial do processo sempre está relacionada com a temperatura ambiente $\left(25^{\circ} \mathrm{C}\right)$. A carga (borra de óleo) utilizada para cada reação foi de aproximadamente 40 gramas $(\mathrm{g})$. Após a reação, o Produto líquido foi lavado com água destilada $\left(\mathrm{a} 70{ }^{\circ} \mathrm{C}\right)$ para a retirada de resíduos do catalisador seguida de uma decantação em um funil de separação para a remoção da fase aquosa.

Nos experimentos foi avaliado a influência dos parâmetros de processo como teor de catalisador $\left(5\right.$ e $10 \% \mathrm{~m} . / \mathrm{m}$.) na temperatura de craqueamento de $440^{\circ} \mathrm{C}$, no rendimento e qualidade dos produtos líquidos orgânicos (PLOs), através da caracterização físico-química (índice de acidez, índice de saponificação, índice de refração e densidade) e análise composicional por FITIR.

\subsection{Caracterização físico-química do PLO}

As propriedades Físico-químicas dos PLOs foram realizadas conforme a norma ANP $\mathrm{N}^{\circ} 65$ para o óleo diesel S 10. A densidade das amostras foi determinada pelo método da ABNT NBR 7148. Empregaram-se métodos oficiais da American Oil Chemistry Society (AOCS) para a determinação do Índice de Acidez (Cd 3d-63), Índice de Refração (Cc 7-25) e Índice de saponificação (Cd 3-25).

\subsection{Espectroscopia de infravermelho}

Os espectros de absorção na região do infravermelho das amostras foram obtidos com o espectrômetro de infravermelho por Transformada de Fourier FT-IR (Shimadzu, modelo Prestige 21). As amostras líquidas foram adicionadas entre as placas de $\mathrm{KBr}$, utilizando-se pipetas e as placas eram montadas com uma leve pressão sobre o líquido visando garantir a uniformidade da película formada. A resolução espectral utilizada foi $\mathrm{de} 16 \mathrm{~cm}^{-1}$ e faixa de varredura foi de 500 a $4000 \mathrm{~cm}^{-1}$. 


\section{RESULTADOS E DISCUSSÃO}

\subsection{Análises do catalisador}

O difratograma do carbonato de sódio de grau comercial está representado na Figura 3.

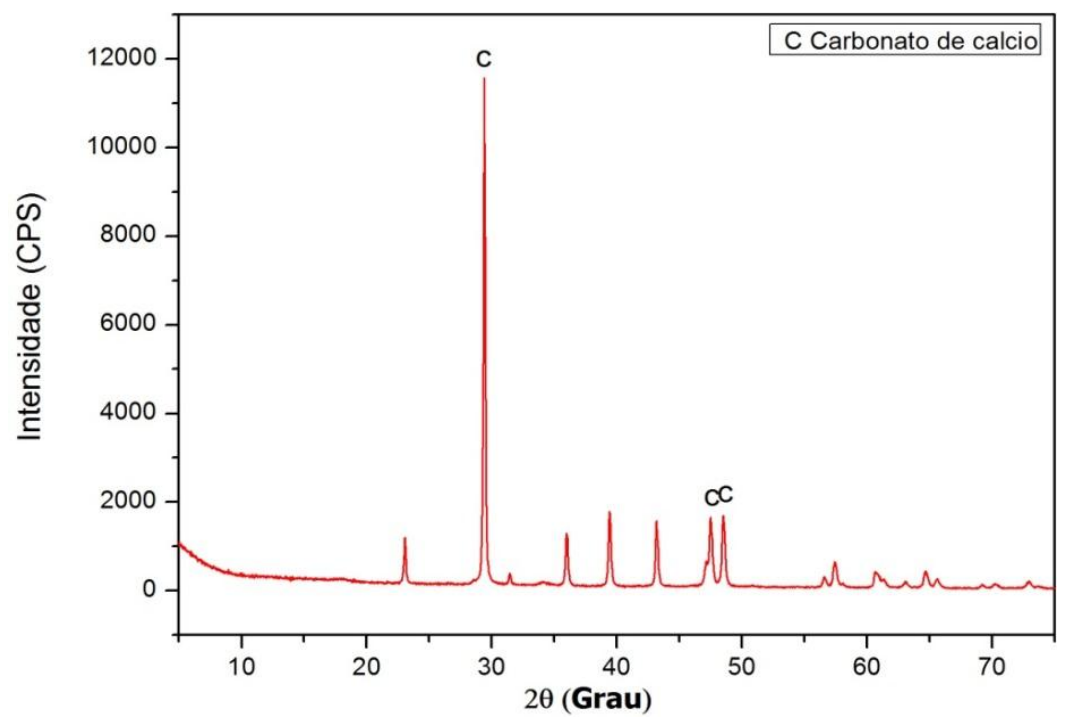

Figura 3 - Difratograma do carbonato de Cálcio de grau comercial

Os três picos de maior intensidade foram observados em $2 \theta$ de 29,4; 47,6 e 48,4 ${ }^{\circ}$, referentes à fase do carbonato de cálcio (calcita). Estes picos apresentam base estreita e de alta intensidade.

A Figura 4 apresenta as curvas térmica diferencial (DTA) e Termogravimétrica (TG) para o carbonato de cálcio anteriormente seco em estufa.

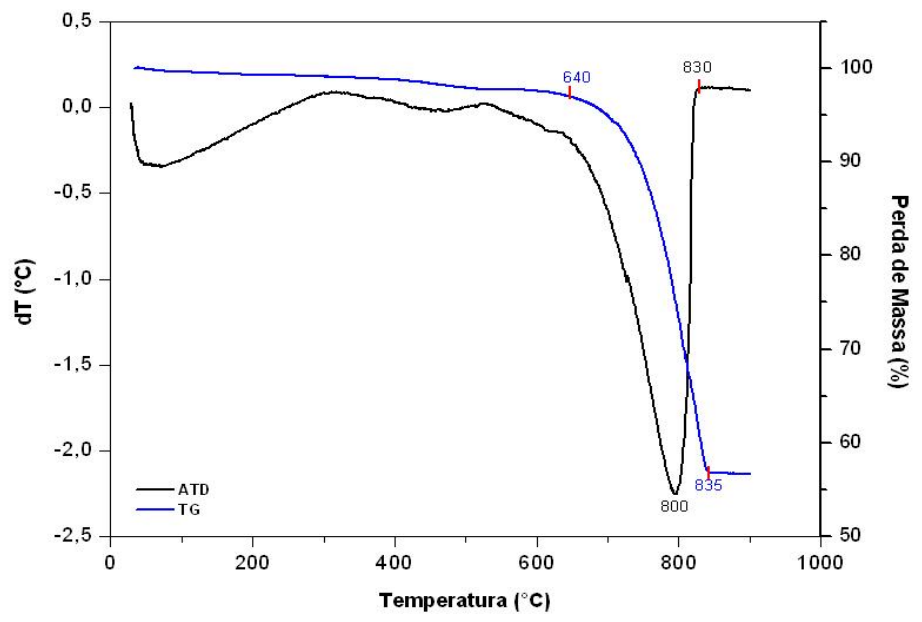

Figura 4 - Termograma do carbonato de cálcio

Neste termograma podemos observar a ausência de um decaimento percentual na massa do 
catalisador até a temperatura de $640^{\circ} \mathrm{C}$. Este resultado possivelmente está associado à ausência da umidade superficial no carbonato de cálcio (até $100^{\circ} \mathrm{C}$ ) e a falta de material impuro que se decompõe até a temperatura de $640{ }^{\circ} \mathrm{C}$. Percebe-se ainda na curva TG, uma redução na massa do carbonato de cálcio em torno de $40 \%$ na faixa de temperatura entre $640^{\circ}-835^{\circ} \mathrm{C}$, possivelmente resultante da decomposição térmica do catalisador (Equação 1), sendo corroborado pela presença do pico endotérmico intenso na curva DTA, com perda máxima ocorrendo em $800^{\circ} \mathrm{C}$.

$$
\mathrm{CaCO}_{3} \rightarrow \mathrm{CaO}+\mathrm{CO}_{2}
$$

\subsection{Caracterização do PLO}

A Tabela 1 apresenta as características físico-químicas dos Produtos líquidos orgânicos obtido do craqueamento da borra de neutralização.

Tabela 1. Características físico-químicas dos Produtos Líquidos Orgânicos

\begin{tabular}{lcccc}
\hline \multirow{2}{*}{$\begin{array}{c}\text { Características } \\
\text { Físico-Químicas }\end{array}$} & Unidade & $\left(5 \% \mathrm{CaCO}_{3} ;\right.$ & $\left(10 \% \mathrm{CaCO}_{3} ;\right.$ & $\mathrm{ANP} \mathrm{N}^{\circ} 65$ \\
\cline { 3 - 5 } & & $\left.\mathrm{T}=440^{\circ} \mathrm{C}\right)$ & $\left.\mathrm{T}=440^{\circ} \mathrm{C}\right)$ & $($ Diesel S10) \\
Índice de acidez & $\mathrm{mg} \mathrm{KOH} / \mathrm{g}$ & 44,37 & $*$ & $* *$ \\
Índice de refração & & 1,449 & 1,445 & $* *$ \\
$\begin{array}{l}\text { Densidade } \\
\text { Índice de }\end{array}$ & $\mathrm{g} / \mathrm{ml}$ & 0,849 & 0,830 & $0,82-0,88$ \\
saponificação & $\mathrm{mg} \mathrm{KOH} / \mathrm{g}$ & 101,04 & 44,605 & $* *$ \\
\hline
\end{tabular}

* Não foi possível realizar em virtude da mínima quantidade de amostra.

**A norma não estabelece valores para estas propriedades.

As densidades dos PLO's mostradas na Tabela 1 apresentam conformidade nos valores de densidade especificada pela norma ANP $\mathrm{N}^{\circ} 65$ para o óleo diesel S 10. Ao analisar a influencia do aumento do teor de catalisador no processo, observou-se uma redução significativa na propriedade de índice de saponificação (em torno de $44 \%$ ). Este resultado possivelmente está associado ao processo de craqueamento secundário (reações 3 e 4 da Figura 2), onde os ácidos graxos livres podem ser convertidos diretamente em hidrocarbonetos, através das reações de descarboxilação ou descarbonilação (Xu et al.,2013). Além disso, ao relacionar o resultado obtido do índice acidez com o valor obtido por Xu et al.(2013), sendo obtido o valor de $79 \mathrm{mg} \mathrm{KOH} / \mathrm{g}$ no processo de craqueamento catalítico do óleo de soja utilizado catalisador básico, foi constatado que o produto líquido a partir da borra de neutralização apresenta valores relativamente baixos para o índice de acidez (ácidos graxos livres). O aumento no teor de catalisador favoreceu na formação de compostos mais leves (hidrocarbonetos de cadeia curta), observados na redução da densidade e índice de refração.

Os rendimentos dos Produtos Líquidos orgânicos (biocombustível), de acordo a Tabela 2, foram obtidos a partir do balanço de massa, assumindo que a operação no reator é isotérmica e regime estacionário. $\mathrm{O}$ resíduo no reator foi pesado para obter o rendimento de coque, enquanto o rendimento do biogás foi obtido por diferença considerando um rendimento de $100 \%$. 
Tabela 2. Rendimentos dos produtos do craqueamento

\begin{tabular}{lcc}
\hline & \multicolumn{2}{c}{ Rendimento (\%) } \\
\cline { 2 - 3 } PLO & Exp.1 $\left(5 \% \mathrm{CaCO}_{3}\right)$ & Exp.2 $\left(10 \% \mathrm{CaCO}_{3}\right)$ \\
Resíduo sólido & 67,69 & 35,21 \\
Gases não condensáveis* & 15,96 & 38,02 \\
\hline
\end{tabular}

O rendimento do produto líquido apresenta uma relação significativa com o teor de catalisador, onde o aumento no teor de catalisador proporcionou na redução do Produto líquido, e no aumento do resíduo sólido. Os espectros de infravermelho do PLO foram apresentados na Figura 5.

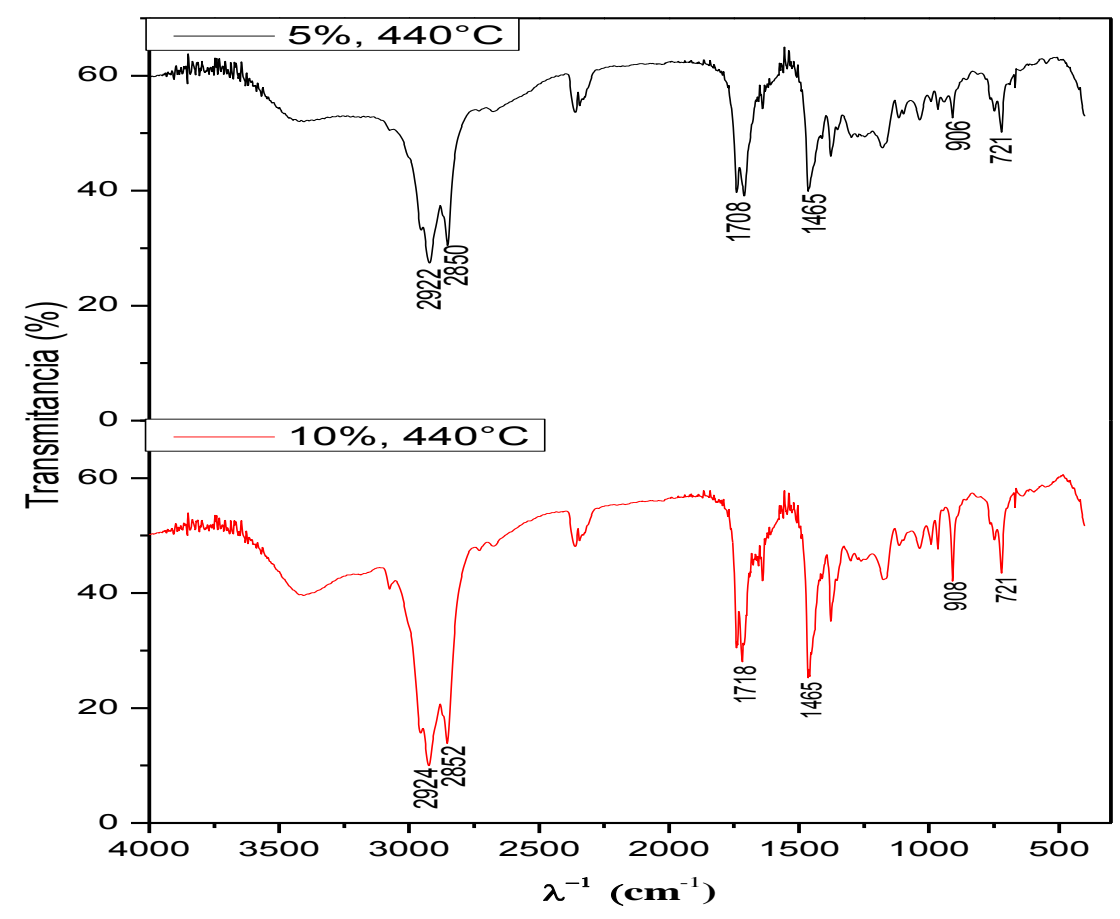

Figura 5 - Espectrogramas de Infravermelho dos PLOs.

Os espectros obtidos apresentam uma banda intensa na região de $1630 \mathrm{~cm}^{-1}$ e $1820 \mathrm{~cm}^{-1}$, correspondente à banda de deformação axial da carbonila $(\mathrm{C}=\mathrm{O})$. Nesta região os picos de 1710 $\mathrm{cm}^{-1}, 1715 \mathrm{~cm}^{-1}$ e $1720 \mathrm{~cm}^{-1}$ indicam a presença das cetonas. No Experimento $2\left(10 \%, 440^{\circ} \mathrm{C}\right)$ observa-se a presença de um estiramento referente à deformação axial da ligação $\mathrm{C}=\mathrm{C}$ em 1643 $\mathrm{cm}^{-1}$, caracterizando a presença de olefina. Todos os espectros apresentam bandas de deformação angular fora do plano da ligação C-H próximo de $908 \mathrm{~cm}^{-1}$ e $721 \mathrm{~cm}^{-1}$ assim como as bandas entre $2922 \mathrm{~cm}^{-1}$ e $2852 \mathrm{~cm}^{-1}$, referentes às deformações axiais alifáticas das ligações $\mathrm{C}-\mathrm{H}$ do grupo metileno $\left(\mathrm{CH}_{2}\right)$ e metila $\left(\mathrm{CH}_{3}\right)$. As bandas próximas de $1375 \mathrm{~cm}^{-1}$ estão relacionadas à presença de deformação angular simétrica das ligações $\mathrm{C}-\mathrm{H}$ do grupo metila. Também é possível notar nestes espectros a presença da hidroxila $(\mathrm{O}-\mathrm{H})$, caracterizada pela banda de deformação axial intensa e larga compreendida entre $3200-2500 \mathrm{~cm}^{-1}$. 


\section{CONCLUSÕES}

Os resultados apresentados mostraram uma rota eficiente para a produção de biocombustível, utilizando um resíduo obtido na etapa de desacidificação do óleo de palma. $\mathrm{Na}$ análise da influencia do teor de catalisador foi observado que o aumento do mesmo favoreceu na redução do rendimento e na diminuição do tamanho das cadeias dos compostos formados. Nos espectros de infravermelho foi constatado a presença de compostos oxigenados (produtos indesejáveis), além de hidrocarbonetos parafinicos (alcanos) e hidrocarbonetos olefínicos (alcenos).

\section{REFERÊNCIAS}

ABREU, D. S. A. Craqueamento termocatalítico borra de neutralização do óleo de palma (Elaeis guineensis) em escala piloto. Dissertação (Mestrado em Engenharia Química) Universidade Federal do Pará. Belém, 2013.

ANP - Agência Nacional de Petróleo, Gás Natural e Biocombustíveis. Resolução nº 65, de 06 de novembro de 2011. Diário Oficial da União, Brasília, DF.

CHANG, C. C., WAN, S. W. Chinas motor fuels from tung oil. Ind. Eng. Chem, v. 39, n. 12, 1543-1548, 1947.

GUSMÃO, J. et al. Utilization of vegetable oils as an alternative source for diesel-type fuel. Catalysis Today. v. 5, n. 4, p. 533-534, 1989.

IDEM, R. O.; Katikaneni, S. P. R.; Bakhshi, N. N. Energy and Fuel, v. 10, p.1150, 1996.

NAM, L. T. H ; VINH, T. Q.; LOAN, N. T. T.; THO, V. D. S.; YANG, X. Y.; SU, B. L. Preparation of bio-fuels by catalytic cracking reaction of vegetable oil sludge. Fuel, v. 90, p. 1069-1075, 2011

PARK, J.; KIM, D.; WANG, Z.; LEE, J.; PARK, S. Production of biodiesel from soap stock using an ion-exchange sesin catalyst. Koreann Journal Chem Eng. V,25, n.6, p 13501354, 2008.

RATTON, A. R. Produção de hidrocarbonetos a partir do craqueamento de resíduos provenientes de caixa de gordura. 2012. Dissertação (Mestrado em Ciências em Química) - Instituto Militar de Engenharia. Rio de Janeiro, 2012.

SUAREZ, P. A. Z.; SANTOS, A. L. F.; RODRIGUES, J. P.; MELQUIZEDEQUE, B. A. Biocombustíveis a partir de óleos e gorduras: Desafios tecnológicos para viabilizá-los. Química nova, v. 32, n. 3, 768, 2009

TWAIQ, F. A.; MOHAMED, A.R.; BHATIA, S. Liquid hydrocarbon fuels from palm oil by catalytic cracking over aluminosilicate mesoporous catalysts with various $\mathrm{Si} / \mathrm{Al}$ ratios. Microporous and Mesoporous Materials. n. 64, p. 95-107, 2003.

XU, J.; JIANG, J.; ZHANG, T.; DAI, W. Biofuel Production from Catalytic Cracking of Triglyceride Materials Followed by an Esterification Reaction in a Scale-up Reaction. Energy Fuels. Aceito em 24 de Dezembro, 2012. 